\title{
Physical mechanics investigation into carbon utilization and storage with enhancing shale oil and gas recovery
}

\author{
ZHAO YaPu ${ }^{1,2 *}$ \\ ${ }^{1}$ State Key Laboratory of Nonlinear Mechanics, Institute of Mechanics, Chinese Academy of Sciences, Beijing 100190, China; \\ ${ }^{2}$ School of Engineering Science, University of Chinese Academy of Sciences, Beijing 100049, China
}

Received November 16, 2021; accepted December 12, 2021; published online December 21, 2021

Citation: Zhao Y P. Physical mechanics investigation into carbon utilization and storage with enhancing shale oil and gas recovery. Sci China Tech Sci, 2022,
65: 490-492, https://doi.org/10.1007/s11431-021-1985-y

Over the last decade, the boom in hydrocarbon recovery from shale formations has revolutionized the world energy landscape [1-3]. This unconventional energy contributes to lower carbon dioxide $\left(\mathrm{CO}_{2}\right)$ and other criteria pollutant emissions. However, its extraction technologies, namely horizontal drilling and hydraulic fracturing (fracking), pose environmental risks. To address this environmental controversy, an option is to use supercritical $\mathrm{CO}_{2}$ to achieve waterless fracking. This is a feasible, economic, and sustainable method of shale gas exploitation and enables carbon sequestration to contribute to carbon neutrality and/or carbon peaking. However, many challenges remain to overcome, such as the impact of supercritical $\mathrm{CO}_{2}$ on shale, the mechanism and efficiency of the displacement, as well as the spontaneity and the thermodynamic properties of the displacement process. Against the above background and using the new concept of "mechano-energetics" depicted in Figure 1, the Zhao group [4-7] abstracted the key scientific issues in the complex shale and investigated the physical-chemical mechanisms of displacing $\mathrm{CH}_{4}$ by $\mathrm{CO}_{2}$ in terms of the experiment, simulation, and theory, as depicted in Figure 2.

It is of critical importance to make clear the impact of supercritical $\mathrm{CO}_{2}$ on shale, especially its nanopores that are responsible for the generation, adsorption, transport, and migration of hydrocarbon. Huang et al. [4] discovered that after supercritical $\mathrm{CO}_{2}$ adsorption, the total pore volume of shale decreases by up to $20 \%$, and the specific surface area

*Corresponding author (email: yzhao@imech.ac.cn) decreases by up to $36 \%$. The volume of nanopores in the $0.85-2.0 \mathrm{~nm}$ range, in particular, decreased by up to $60 \%$. Composition analysis reveals that different minerals in the shale have undergone different changes as a result of supercritical $\mathrm{CO}_{2}$ adsorption. They looked at how the shale's morphology changed and discovered that nanopores are either closed or newly opened, with more closed pores than new ones. This remarkable phenomenon, known as adsorption-induced pore blocking, is caused by $\mathrm{CO}_{2}$-reservoirwater physisorption, associative chemisorption, and dissociative chemisorption (Figure 2(a)). $\mathrm{CO}_{2}$ is most likely to be adsorbed to the nanopores and diffuses into solid organic matters (kerogen and asphalt), causing the swelling of the matters and the pore blocking by the physisorption. Furthermore, $\mathrm{CO}_{2}, \mathrm{H}_{2} \mathrm{O}$, and some mineral fragments may react to form new productions, which may block nanopores through this associative chemisorption. For the dissociative chemisorption, $\mathrm{CO}_{2}$ dissolves in water to dissociate $\mathrm{H}^{+}$, which further dissolves some minerals of the shale. Meanwhile, the rock forms a rough texture. And as a result, the pore volume may either increase or decrease, and the surface will get rougher in the process.

To gain insight into the physical mechanism of the $\mathrm{CO}_{2}$ enhanced shale gas recovery, Yuan et al. [5] studied this recovery process at the atomic level using molecular dynamics (MD) simulations (Figure 2(b)). As adsorption is mainly in organic pores, carbon-based substrate, which has a similar heat of adsorption to that on organics, was chosen as the model for the study of the displacement mechanism. The 


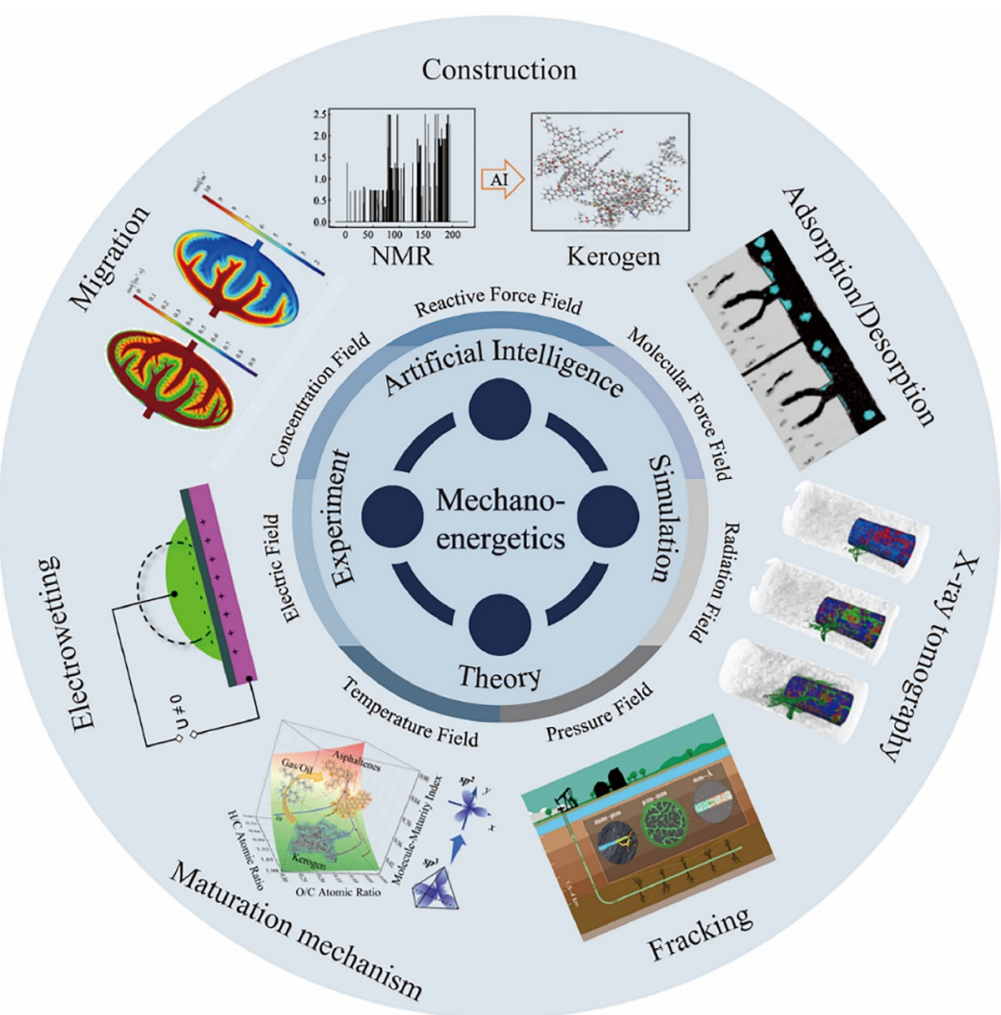

Figure 1 (Color online) Schematic of mechano-energetics. It is coined to study the efficient development and utilization of energy based on mechanics, coupling with a force field, radiation field, temperature field, and electric field by theory, experiment, simulation, and artificial intelligence methods.

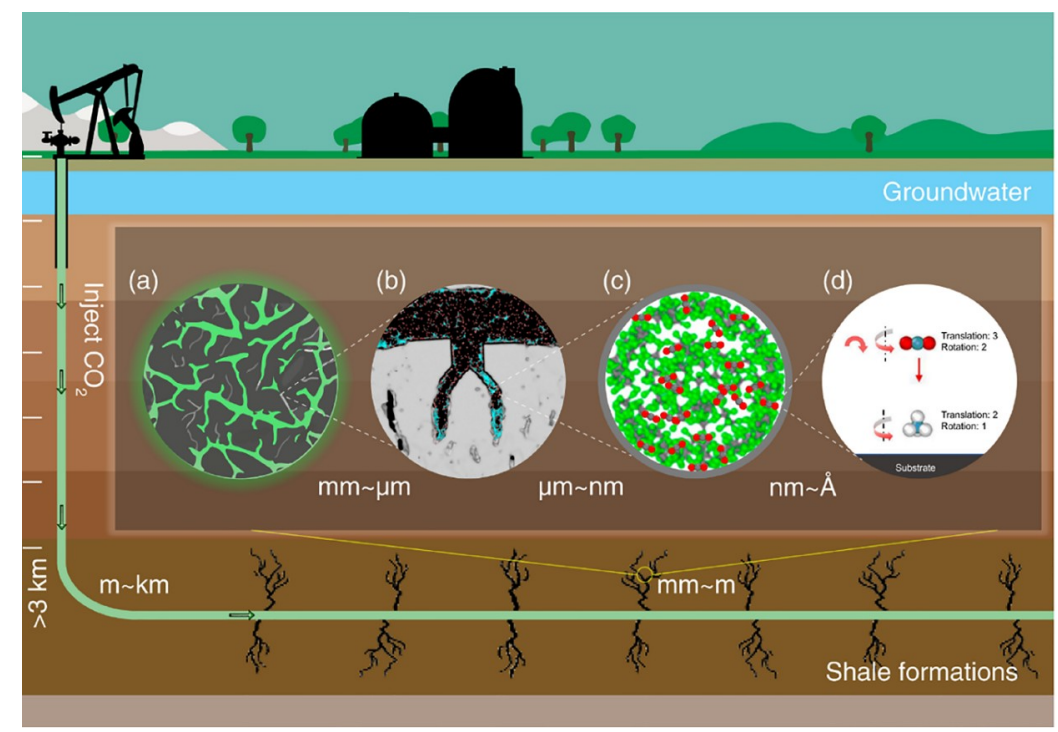

Figure 2 (Color online) Carbon sequestration with $\mathrm{CO}_{2}$ enhancing shale oil and gas recovery. (a) Mineralization storage of $\mathrm{CO}_{2}$ as supercritical $\mathrm{CO}_{2}-$ reservoirs-water interactions, resulting in adsorption-induced pore blocking of the formations; (b) storage state of molecules in nano-channel; (c) displacing $\mathrm{CH}_{4}$ by $\mathrm{CO}_{2}$; (d) degrees of freedom of the molecules before the displacement.

adsorption of $\mathrm{CH}_{4}$ and $\mathrm{CO}_{2}$ was compared in terms of energy, configuration, structure, capacity, etc. The process and efficiency of the displacement of $\mathrm{CH}_{4}$ by $\mathrm{CO}_{2}$ injection in carbon nanotubes (CNTs) were investigated. The adsorption energy of $\mathrm{CO}_{2}$ on a carbon substrate is approximately $30 \%$ lower than that of $\mathrm{CH}_{4}$, indicating that $\mathrm{CO}_{2}$ is more readily ad- sorbed on carbon substrate than $\mathrm{CH}_{4}$ and could be a good candidate for the displacement of $\mathrm{CH}_{4}$. First, the displacement of one $\mathrm{CH}_{4}$ molecule was investigated by injecting one $\mathrm{CO}_{2}$ molecule onto a carbon substrate. The study revealed a decrease in the energy barrier required for the displacement process as the displacement angle increases. In addition, a 
greater energy barrier is required to displace one $\mathrm{CH}_{4}$ molecule from one adsorption layer than to displace one isolated $\mathrm{CH}_{4}$ adsorbed on a substrate. Investigating the desorption and displacement of pre-adsorbed $\mathrm{CH}_{4}$ in the nano-channels revealed that injecting $\mathrm{CO}_{2}$ into the nano-channels enhanced the recovery of $\mathrm{CH}_{4}$ by at least $14.78 \%$ compared to the pressure drawdown method. In addition, due to the competition between the adsorption energy and potential well depth, an optimum diameter was found to exist, making the $\mathrm{CO}_{2}$-injected method the most efficient.

To provide further insight into the displacement processes by different supercritical fluids, Lin et al. [6] compared the recovery dynamics of the CNT-confined $\mathrm{CH}_{4}$ with water $\left(\mathrm{H}_{2} \mathrm{O}\right), \mathrm{CO}_{2}$, and nitrogen $\left(\mathrm{N}_{2}\right)$, by performing MD simulations. The theoretical analysis yielded a simple yet effective method for calculating the stress tensor caused by adsorption or desorption. When the adsorption energies are compared, $\mathrm{CO}_{2}$ is the best candidate for displacing $\mathrm{CH}_{4}$ on a carbonbased surface. Furthermore, the mechanism of $\mathrm{CO}_{2}$ rotation in the displacement process has been discussed, and a critical point exists when the $\mathrm{CO}_{2}$ molecule rotates from vertical to horizontal. The displacement processes of the confined $\mathrm{CH}_{4}$ in the nano-channel by the three supercritical fluids demonstrate that the $\mathrm{CH}_{4}$ molecules close to the center of the nano-channel were displaced firstly and the adsorbed $\mathrm{CH}_{4}$ molecules close to the nano-channel wall were displaced gradually. Furthermore, the displacement efficiency of $\mathrm{H}_{2} \mathrm{O}$, $\mathrm{CO}_{2}$, and $\mathrm{N}_{2}$ were $61.6,96.9$, and 64.8 percent, respectively. Thus, this study reveals that supercritical $\mathrm{CO}_{2}$ (Figure 2(c)) has an overwhelming efficiency advantage among these three fluids. In addition to carbon-based nanopores, it has been shown that pore surface chemistry, humidity, and pore type can affect the transport properties of $\mathrm{CH}_{4}$ in nanopores [8]. However, the properties of $\mathrm{CO}_{2}$ displacing $\mathrm{CH}_{4}$ in these different nanopores need to be further investigated.

The majority of the existing studies on the phenomenological or qualitative or quantitative analysis of shale gas recovery processes have been based on simulation or experimental methods. Lin et al. [7] studied the thermodynamic mechanisms, such as entropy-driven and enthalpy-driven, in the processes of displacement during shale gas exploitation. The space group of molecules was used to analyze the changes in the symmetry of $\mathrm{CH}_{4}$ and $\mathrm{CO}_{2}$ adsorbed on the substrate surface. By analyzing changes in translational and rotational entropy of molecules, the entropy changes in adsorption and displacement processes were calculated (Figure 2(d)). An examination of the enthalpy changes during the displacement of $\mathrm{CH}_{4}$ by various displacement media (i.e., $\mathrm{CO}_{2}, \mathrm{H}_{2} \mathrm{O}$, and $\mathrm{N}_{2}$ ) reveals that $\mathrm{CH}_{4}$ displaced by $\mathrm{CO}_{2}$ is an exothermic process, whereas $\mathrm{CH}_{4}$ displaced by the other two media are endothermic processes. At $300 \mathrm{~K}$, the changes of the Gibbs free energy of replacing $\mathrm{CH}_{4}$ with $\mathrm{CO}_{2}, \mathrm{H}_{2} \mathrm{O}$, and $\mathrm{N}_{2}$ are $-19.72,15.57$, and $-11.39 \mathrm{~kJ} / \mathrm{mol}$, respectively, when the enthalpy and entropy changes are combined. Therefore, displacing $\mathrm{CH}_{4}$ by $\mathrm{CO}_{2}$ is a spontaneous process with enthalpy and entropy dual-driven, displacing $\mathrm{CH}_{4}$ by $\mathrm{N}_{2}$ is a spontaneous process with entropy-driven, and displacing $\mathrm{CH}_{4}$ by $\mathrm{H}_{2} \mathrm{O}$ is an endothermic and nonspontaneous process. Although the processes in shale gas extraction are unlikely to be the same as the ideal conditions considered in the research, the study provides a new perspective based on thermodynamics to explore the efficiency of displacing shale gas by injecting different supercritical fluids.

Improved understanding of shale changes in supercritical $\mathrm{CO}_{2}$ environment, especially its nanopores changes, will help effectively design and manage $\mathrm{CO}_{2}$-fracking. These changes will have a negative impact on hydrocarbon production and $\mathrm{CO}_{2}$ storage, resulting in a complex system that restricts and influences each other. As a practical application, this research aids in determining the efficiency of hydrocarbon production via $\mathrm{CO}_{2}$-fracking, as well as the potential for $\mathrm{CO}_{2}$ storage in shale formations. The mechanism and efficiency of displacing $\mathrm{CH}_{4}$ at the atomic level are clarified by these MD studies. Thermodynamic and statistical analyses provide theoretical support for the spontaneity and efficiency of displacing $\mathrm{CH}_{4}$ by $\mathrm{CO}_{2}$, as well as a deeper understanding of the kinetic mechanism of shale gas displacement. These studies not only provide important experimental and theoretical parameters for shale oil/gas extraction but also point the way toward carbon sequestration. Ultimately, it is expected to contribute to the achievement of carbon neutrality/peak carbon targets.

This work was supported by the National Natural Science Foundation of China (Grant Nos. 12032019, 11872363, and 51861145314), the Chinese Academy of Sciences (CAS) Key Research Program of Frontier Sciences (Grant No. QYZDJ-SSW-JSC019), and the CAS Strategic Priority Research Program (Grant No. XDB22040401).

1 Zhan J, Chen Z X, Zhang Y, et al. Will the future of shale reservoirs lie in $\mathrm{CO}_{2}$ geological sequestration? Sci China Tech Sci, 2020, 63: 1154-1163

2 Liu C, Shen Y K, Zhang J N, et al. Production analysis in shale gas reservoirs based on fracturing-enhanced permeability areas. Sci China-Phys Mech Astron, 2019, 62: 104611

3 Wang T, Ye X, Liu Z L, et al. An optimized perforation clusters spacing model based on the frictional shale layer's debonding. Sci China-Phys Mech Astron, 2019, 62: 114621

4 Huang X, Zhao Y P, Wang X, et al. Adsorption-induced pore blocking and its mechanisms in nanoporous shale due to interactions with supercritical $\mathrm{CO}_{2}$. J Pet Sci Eng, 2019, 178: 74-81

5 Yuan Q, Zhu X, Lin K, et al. Molecular dynamics simulations of the enhanced recovery of confined methane with carbon dioxide. Phys Chem Chem Phys, 2015, 17: 31887-31893

6 Lin K, Yuan Q, Zhao Y P, et al. Which is the most efficient candidate for the recovery of confined methane: Water, carbon dioxide or nitrogen? Extreme Mech Lett, 2016, 9: 127-138

7 Lin K, Zhao Y P. Entropy and enthalpy changes during adsorption and displacement of shale gas. Energy, 2021, 221: 119854

$8 \mathrm{Yu} \mathrm{H}, \mathrm{Xu} \mathrm{H} \mathrm{Y,} \mathrm{Fan} \mathrm{J} \mathrm{C,} \mathrm{et} \mathrm{al.} \mathrm{Transport} \mathrm{of} \mathrm{shale} \mathrm{gas} \mathrm{in} \mathrm{microporous/}$ nanoporous media: molecular to pore-scale simulations. Energy Fuels, 2021, 35: 911-943 